\title{
Plasma Brain-Derived Neurotropic Factor Levels Are Associated with Aging and Smoking But Not with Future Dementia in the Rotterdam Study
}

\author{
Sara Galle ${ }^{\mathrm{a}, \mathrm{b}, *}$, Silvan Licher ${ }^{\mathrm{b}}$, Maarten Milders ${ }^{\mathrm{a}}$, Jan Berend Deijen ${ }^{\mathrm{a}, \mathrm{c}}$, Erik Scherder ${ }^{\mathrm{a}}$, \\ Madeleine Drent ${ }^{\mathrm{a}, \mathrm{d}},{\text { Arfan } \text { Ikram }^{\mathrm{b}} \text { and Cornelia van Duijn }}^{\mathrm{b}, \mathrm{e}, \mathrm{f}}$ \\ ${ }^{a}$ Department of Clinical, Neuro- and Developmental Psychology, Vrije Universiteit Amsterdam, Amsterdam, \\ The Netherlands \\ ${ }^{\mathrm{b}}$ Department of Epidemiology, Erasmus Medical Center, Rotterdam, The Netherlands \\ ${ }^{\mathrm{c}}$ Hersencentrum Mental Health Institute, Amsterdam, The Netherlands \\ ${ }^{\mathrm{d}}$ Department of Internal Medicine, Endocrinology Section, Amsterdam University Medical Center, Amsterdam, \\ The Netherlands \\ ${ }^{\mathrm{e}}$ Nuffield Department of Population Health, University of Oxford, Oxford, United Kingdom \\ ${ }^{\mathrm{f}}$ Big Data Institute, Li Ka Shing Centre for Health Information and Discovery, Oxford, United Kingdom
}

Handling Associate Editor: Yadong Huang

Accepted 18 January 2021

Pre-press 23 February 2021

\begin{abstract}
.
Background: Brain-derived neurotropic factor (BDNF) plays a vital role in neuronal survival and plasticity and facilitates long-term potentiation, essential for memory. Alterations in BDNF signaling have been associated with cognitive impairment, dementia, and Alzheimer's disease. Although peripheral BDNF levels are reduced in dementia patients, it is unclear whether changes in BDNF levels precede or follow dementia onset.

Objective: In the present study, we examined the association between BDNF plasma levels and dementia risk over a follow-up period of up to 16 years.

Methods: Plasma BDNF levels were assessed in 758 participants of the Rotterdam Study. Dementia was assessed from baseline (1997-1999) to follow-up until January 2016. Associations of plasma BDNF and incident dementia were assessed with Cox proportional hazards models, adjusted for age and sex. Associations between plasma BDNF and lifestyle and metabolic factors are investigated using linear regression.

Results: During a follow up of 3,286 person-years, 131 participants developed dementia, of whom 104 had Alzheimer's disease. We did not find an association between plasma BDNF and risk of dementia (adjusted hazard ratio 0.99; 95\% CI $0.84-1.16)$. BDNF levels were positively associated with age $(\mathrm{B}=0.003, \mathrm{SD}=0.001, p=0.002)$, smoking $(\mathrm{B}=0.08$, $\mathrm{SE}=0.01, p=<0.001)$, and female $\operatorname{sex}(\mathrm{B}=0.03, \mathrm{SE}=0.01, p=0.03)$, but not with physical activity level $(\mathrm{B}=-0.01, \mathrm{SE}=0.01$, $p=0.06)$.
\end{abstract}

Conclusion: The findings suggest that peripheral BDNF levels are not associated with an increased risk of dementia.

Keywords: Aging, Alzheimer's disease, brain-derived neurotropic factor, dementia, genetic epidemiology

\footnotetext{
*Correspondence to: Sara A. Galle, Vrije Universiteit Amsterdam - Faculteit der Gedrags- en Bewegingswetenschappen, t.a.v. Sara A. Galle MF-B535, Van der Boechorststraat 7-9, 1081 BT
}

Amsterdam, The Netherlands. Tel.: +31 205988 769; E-mail: s.a.galle@vu.nl. 


\section{INTRODUCTION}

Brain-derived neurotropic factor (BDNF) is the most widely distributed neurotropic factor, that supports physiological functioning in the central nervous system and the periphery [1-3]. It plays a vital role in neuronal survival and plasticity of cholinergic and dopaminergic neurons in the cortex [4-8] and facilitates hippocampal and cortical long-term potentiation, essential for memory acquisition and consolidation [9-11].

BDNF's neurotropic effects are exerted by binding to the tyrosine receptor kinase B (TrkB). Breakdown of the BDNF-TrkB signaling pathway has been associated with poorly differentiated neurons, loss of synaptic connectivity, and cognitive impairment [12]. Reduced serum BDNF has been related to smaller hippocampal volumes as well as poorer memory performance in healthy elderly. Higher levels of BDNF, on the other hand, have been related to better learning and memory [13, 14].

The BDNF-TrkB signaling pathway is also implicated in the pathogenesis of Alzheimer's disease (AD) [15]. Postmortem, AD patients show decreased levels of BDNF and its receptor in the frontal cortex and hippocampus [16] and reduced expression of the BDNF gene in the hippocampus and the entorhinal cortex [17], compared to neurologically nonimpaired controls. The hippocampus, frontal and entorhinal cortex are consistently affected in the earliest stages of the disease.

Despite consistent findings in pathological studies, the findings of clinical studies investigating the association of BDNF with AD or mild cognitive impairment (MCI) have been far from consistent. While various studies reported lower peripheral BDNF levels in AD patients compared to healthy controls, other studies showed an inverse or no association [18-22]. A meta-analysis of 15 cross-sectional and case-control studies showed significantly lower peripheral serum BDNF levels in AD patients compared to controls [23]. No differences in peripheral BDNF levels were found between patients diagnosed with MCI and healthy controls [23]. Of note is that change in peripheral BDNF levels could only be detected in later stages of disease progression [23]. Investigating plasma-based markers, Elahi et al. found elevated BDNF levels in late-onset $\mathrm{AD}$ patients, that were strongly associated with cognition and gray matter volumes [24].

Because of the cross-sectional design of these case control studies, it is impossible to disentangle whether changes in BDNF levels precede or follow the cognitive decline and onset of dementia. Cohort studies investigating the association between peripheral BDNF levels and future cognitive decline and dementia risk are scarce. Weinstein et al. found that higher peripheral BDNF levels in older adults were protective against the development of AD [25]. However, the association between BDNF and the risk for incident dementia was limited to specific subgroups, i.e., women, older participants ( $>80$ years), and participants with at least a college degree [25]. In AD patients, higher BDNF serum levels were predictive of relatively slower cognitive decline in the following year [26]. Longitudinal studies of cognitive decline in healthy elderly did not provide evidence for an association between peripheral BDNF and rate of decline over 10 years [27, 28].

Besides genetic variation, age, and sex, a proportion of the observed variation in BDNF levels can be attributed to lifestyle factors, (co)morbidities, and the presence of depressive symptoms. Sleep deprivation, depression, diabetes mellitus, and stress have been associated with decreased levels of BDNF [29-33], whereas physical activity, smoking, coronary artery disease, and caloric restriction are associated with elevated BDNF levels [13, 33, 34-41, 42].

In light of the conflicting results regarding the association between BDNF levels and risk of dementia, we examined the long-term association between BDNF plasma levels and dementia risk over a followup period up to 16 years and addressed the association between plasma BDNF, associated comorbidities and a large number of lifestyle exposures.

\section{MATERIALS AND METHODS}

\section{Setting}

This study was embedded within the prospective, population-based Rotterdam Study, ongoing since 1990 in the city of Rotterdam in the Netherlands. The study was designed to study risk factors and determinants of disease in the elderly population. The Rotterdam Study started with an invitation to 10,215 inhabitants of Rotterdam, aged 55 years and older. Of the invitees, 7,983 (78\%) people agreed to participate in the first examinations. The participants were interviewed at home and participated in elaborate physical examinations at the Rotterdam Study research facility in the Ommoord district in Rotterdam. The assessments were repeated every 3 to 5 years. The second follow-up assessment of the first cohort (RSI-3) was 


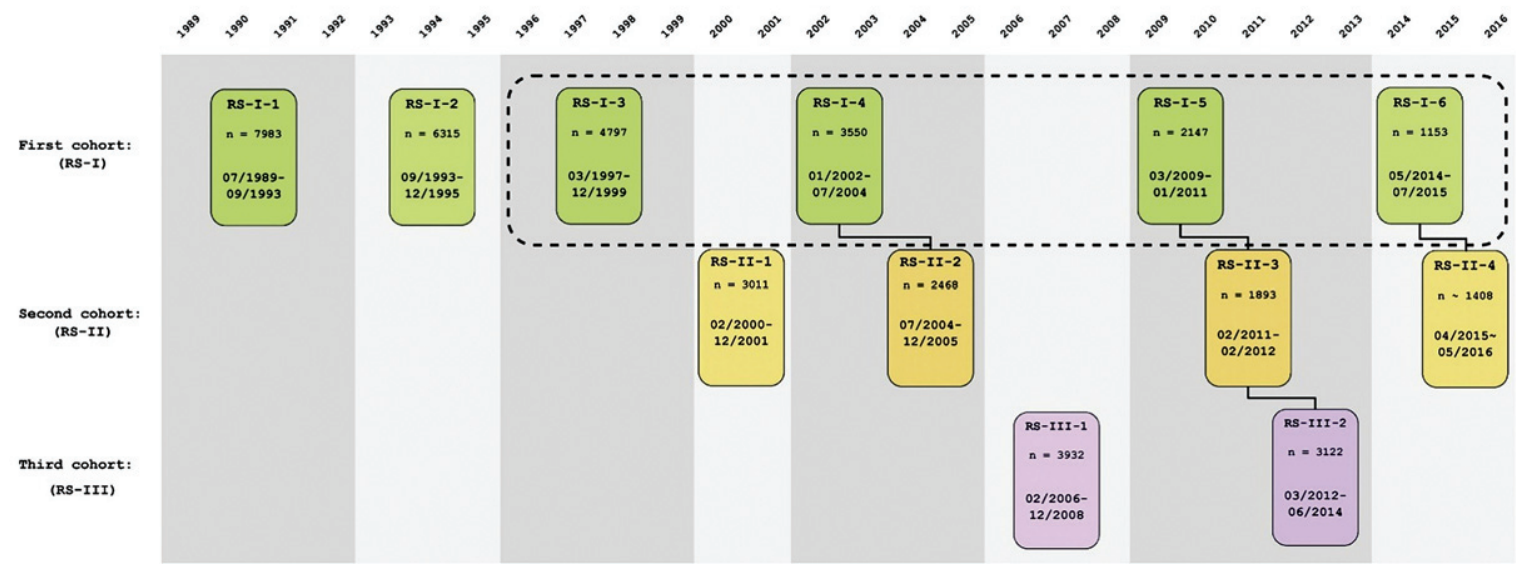

Fig. 1. Diagram of examination cycles of the Rotterdam Study (RS) [43]. RS-I-1 refers to the baseline examination of the original cohort. RS-I-2, RS-I-3, RS-I-4, RS-I-5, and RS-I-6 refer to re-examinations of the original cohort members. The follow-up examinations within the dashed border are included in the present study. RSI-3 was used as baseline.

used as baseline in the present study. A diagram of the cohort cycles of the Rotterdam Study is depicted in Fig. 1. Further details on the objectives and design of the Rotterdam Study have been described elsewhere [43].

The Rotterdam Study has been approved by the Medical Ethics Committee of the Erasmus MC (registration number MEC 02.1015) and by the Dutch Ministry of Health, Welfare and Sport (Population Screening Act WBO, license number 1071272159521-PG). The Rotterdam Study has been entered into the Netherlands National Trial Register (NTR; www.trialregister.nl) and into the WHO International Clinical Trials Registry Platform (ICTRP; www.who. int/ictrp/network/primary/en/) under shared catalogue number NTR6831. All participants provided written informed consent to participate in the study and to have their information obtained from treating physicians.

\section{Participants}

From 1997 to 1999, plasma BDNF levels were measured in blood samples collected at the second follow-up examination of the first cohort (RSI-3) that is considered the baseline measurement for the current study. From the 4,797 individuals who participated in the second follow-up examination, 971 participants were randomly selected for BDNF assessment. Plasma BDNF values below the lower detection limit (11 pg/mL; $\mathrm{N}=191 ; 19.76 \%)$ or more than three standard deviations above the average plasma BDNF value $(\mathrm{N}=1)$ were considered outliers and were excluded from the analyses. Participants diagnosed with dementia at baseline $(\mathrm{N}=14)$ were excluded from the analyses. The data of seven people were excluded from analyses because insufficient data were available to ascertain dementia status at baseline. In total, the data of 758 participants were analyzed, including the data of 131 participants who developed dementia during follow-up. See Fig. 2 for a flowchart of participant selection.

\section{Assessment of plasma BDNF}

Fasting blood samples were obtained at the research center. Citrate plasma $(5 \mathrm{~mL})$ was collected and stored at $-80^{\circ} \mathrm{C}$. In $2008,200 \mu \mathrm{L}$ of citrate plasma from each participant was sent to Myriad RBM, Austin, Texas (http://www.myriadrbm.com) where a multiplex immunoassay on a human multi-analyte profile was performed [44]. Samples were run in duplicates according to the manufacturer's published protocols [45] and met all parameters of quality control as defined by the Clinical Laboratory Standards Institute [46]. Intra-assay variation and percentage missing did not exceed 10\%. Plasma BDNF levels are expressed in picogram per milliliter $(\mathrm{pg} / \mathrm{mL})$. The minimum and maximum detectable dosages were $11 \mathrm{pg} / \mathrm{mL}$ and $26500 \mathrm{pg} / \mathrm{mL}$ respectively.

\section{Assessment of dementia}

Participants were screened for dementia at baseline and follow-up examinations, using a cognitive assessment including the Mini-Mental State Examination (MMSE) [47] and the Geriatric Mental Schedule 


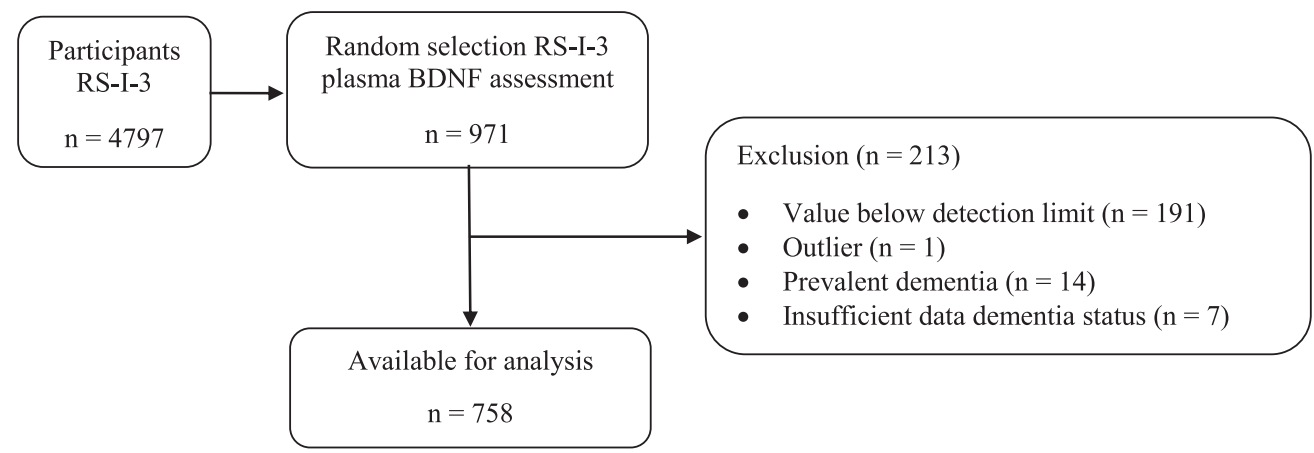

Fig. 2. Flowchart of participant selection from the second follow-up measurement in cohort 1 of the Rotterdam Study (RS-I-3).

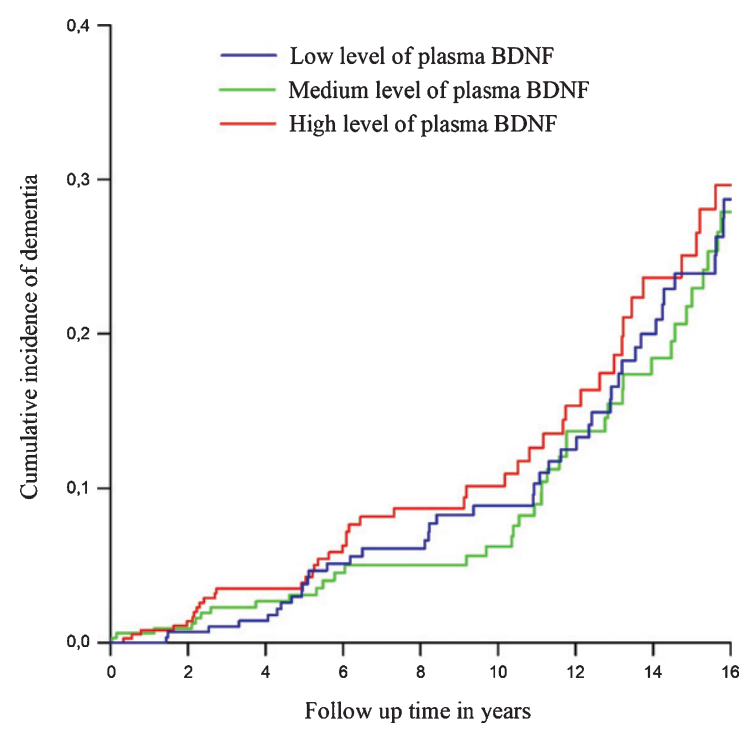

Fig. 3. Cumulative incidence curves of dementia per tertile of plasma Brain Derived Neurotrophic Factor (BDNF), adjusted for age and sex. Tertile 1 represent the lowest levels of plasma BDNF, tertile 2 medium levels and tertile 3 the highest levels.

(GMS) organic level [48]. Participants with a MMSE score lower than 26 or GMS organic level higher than 0 subsequently underwent further investigation and an informant interview including the Cambridge Examination for Mental Disorders in the Elderly (CAMDEX) [49]. A consensus panel led by a consultant neurologist established the final diagnosis dementia or probable AD according to standard criteria for dementia (Diagnostic and Statistical Manual of Mental Disorders III-revised) (American Psychiatric Association, 1987) and AD (National Institute of Neurological and Communicative Disorders and Stroke and the Alzheimer's Disease and Related Disorders Association) [51].
During follow-up, the cohort was under continuous surveillance for dementia incidence through electronic linkage of the database of the Rotterdam Study with medical records from general practitioners and the Regional Institute for Outpatient Mental Health Care. Follow-up for incident dementia is virtually complete until January 1, 2016 (97.6\% of potential person-years).

\section{Assessment of APOE}

Information on $A P O E$ was obtained using polymerase chain reaction on coded DNA samples. APOE $\varepsilon 4$ carrier status was defined as carrier of one or two $\varepsilon 4$ alleles. Missing values for $A P O E \varepsilon 4$ carrier status $(3.83 \%)$ were imputed using regression analyses based on age and sex.

\section{Assessment of physical activity}

Levels of daily physical activity (PA) were assessed at baseline with the Zutphen Physical Activity Questionnaire [52]. The questionnaire was translated into Dutch and validated in a sample of the Zutphen Elderly Study Population [52]. The test-retest reliability of this questionnaire is 0.93 and its correlation with doubly labelled water, the gold standard for measuring PA, is 0.61 [53]. The questionnaire contains questions on walking, cycling, sports, gardening, hobbies, and housekeeping and inventoried the frequency and duration of these activities performed in the previous week. To quantify activity intensity, we assigned metabolic equivalent of task (MET) units to all activities mentioned in the questionnaire according to the 2011 updated version of the Compendium of Physical Activities [54]. Finally, we multiplied MET-values of specific activities with time (in hours) per week spent on that activity to calculate 
MET $h \cdot h \cdot$ week of total PA. Standardized values of total MET-hours of physical activity per week and number of MET-hours spent on moderate to vigorous physical activity were used for analyses. Detailed information on the collection of PA data has been described previously [55].

\section{Assessment of depressive symptoms and anxiety}

We measured depressive symptoms using the validated Dutch version of the Center for Epidemiology Depression Scale (CES-D) [56, 57]. Participants were asked to self-report how often they experienced various depressive symptoms during the previous week. Possible scores ranged from 0 (rarely or never) to 3 (most or all of the time). For items with positive affect, the response categories were reversed. Total scores were summed to a total depressive symptoms score ranging from zero to 60 . The psychometric properties of the scale were found to be good in an older population [57]. The presence of feelings of anxiety was derived from item 10 on the CES-D on which participants were asked how often they had felt anxious during the previous week. Anxiety was than coded as $N o=$ 'never' versus Yes $=$ 'sometimes' or 'most or all of the time'. Missing values for depressive symptoms (5.94\%) and anxiety (1.72\%) were imputed using regression analyses based on age and sex.

\section{Other measurements}

Systolic blood pressure was calculated as the average of two measurements at the right brachial artery using a random-zero sphygmomanometer. Serum glucose, total cholesterol, and high-density lipoprotein (HDL)-cholesterol levels were acquired by an automated enzymatic procedure (Boehringer Mannheim System). To assess diabetes mellitus all participants, except those on anti-diabetic medication, received a glucose drink of $75 \mathrm{mg}$ in $200 \mathrm{~mL}$ water. Participants were classified as having diabetes mellitus if they used any anti-diabetic medication or when the pre-load or post-load serum glucose levels were at or above $11.1 \mathrm{mmol} / \mathrm{l}$. Education level was defined as low (primary, unfinished secondary and lower vocational), middle (secondary or intermediate vocational) and high (higher vocational or university). Body mass index (BMI) was calculated by dividing participants' weight in kilogram by the height in meters. At baseline all participants were asked about their medication use, past and current smoking habits and current alcohol consumption.
Smoking status was categorized into current smoker, former smoker and never smoked. Alcohol consumption was defined as gram per day. Missing values for smoking status $(1.06 \%)$ were imputed using regression analyses based on age and sex.

\section{Statistical analyses}

We examined the association between plasma BDNF and incident dementia in the total sample using Cox proportional hazards models. Plasma BDNF was entered per standard deviation (SD) into the models. To adjust the estimation of the proportional hazard for the competing risk of death an additional competing risk regression was performed [58]. We also studied plasma BDNF in tertiles, using the lowest tertile as reference. The underlying timescale in the Cox proportional hazards models was the followup time, which was defined from the date of blood sample collection (1997-1999) until 1 January 2016. Participants were censored within this period when they were diagnosed with dementia, died, or were lost to follow-up, whichever came first. Analyses were adjusted for age and sex. The proportional hazards assumption was tested with the Schoenfeld residuals test and log-log plots of the survival function, both procedures confirmed that the assumption was met. No outliers were identified. To control bias due to risk factors and co-morbidities that may influence circulating BDNF, educational level, total- and HDL cholesterol, glucose level, presence of diabetes mellitus, body mass index, systolic blood pressure, depressive symptoms, anxiety (y/n), alcohol consumption, smoking status, physical activity level, and $A P O E \varepsilon 4$ carrier status, are investigated as potential confounders. None of the additional covariates qualified as confounder as they did not change the estimate of the model with more than $1 \%$. To investigate possible effect modification by Apolipoprotein E, the (multiplicative) interaction between sex, education, smoking and APOE $\varepsilon 4$ carrier status, and plasma BDNF on dementia risk was tested using interaction terms.

We used a linear regression model to examine the influence of metabolic and lifestyle factors on plasma BDNF levels in the randomly drawn sub-cohort. Effects of medication use on plasma BDNF were studied as potential confounders, including the effects of ACE-inhibitors, anti-hypertensive and anti-thrombotic drugs, serum lipid reducing agents, anti-diabetic, anti-Parkinson, anti-epileptic, anti-inflammatory and anti-rheumatic medication, 
systemic corticosteroids, psycholeptic- and psychoanaleptic agents. Plasma BDNF levels showed a non-normal distribution, with a positive skewness and elevated kurtosis. As $\log 10$ transformation did not change the results, analyses on the non-transformed BDNF values are presented. Analyses were performed using Stata/SE version 16 (StataCorp LLC, College Station, TX, USA).

\section{RESULTS}

Baseline characteristics of the study population are shown in Table 1. During a total follow up of 3,286 person-years of the total sample, 131 participants of the total set developed dementia, of whom 104 were diagnosed with $\mathrm{AD}$, and 27 were diagnosed with other types of dementia including vascular dementia and Parkinson's disease dementia. The incidence rate of 40 cases per 1000 person-years in the present sample lies within the range of the estimated incidence rates in Western Europe for people between the age of 60 and 90 + that varies from 3.1 to $122.4[59,60]$. The average plasma BDNF level is $138.81 \mathrm{pg} / \mathrm{mL}$, with a standard deviation of $160.41 \mathrm{pg} / \mathrm{mL}$. Group means and standard deviations are provided in Table 2.

\section{Cross-sectional associations with BDNF level}

Linear regression analyses on the association between metabolic and lifestyle factors and plasma BDNF in the sub-cohort (Table 3) indicated a positive relation with age $(\mathrm{B}=0.003, \mathrm{SE}=0.001$, $p=0.002)$, female sex $(\mathrm{B}=0.03, \mathrm{SE}=0.01, p=0.03)$, and current smoking $(\mathrm{B}=0.08, \mathrm{SE}=0.01, p<0.001)$. The association between plasma BDNF level and standardized baseline levels of physical activity $(\mathrm{B}=-0.01, \mathrm{SE}=0.01, p=0.06)$ did not reach significance. Total model: $\mathrm{F}(15,742)=2.97, p \leq 0.001$. Plasma BDNF levels at baseline of participants who developed incident $\mathrm{AD}$ during follow-up are higher $(\mathrm{M}=0.15, \mathrm{SD}=0.16)$ than those of participants that were diagnosed with other dementia types during follow-up $(\mathrm{M}=0.09, \mathrm{SD}=0.10) \mathrm{F}(1) 4.08$, $p=0.045$.

Effects of medication use on plasma BDNF were studied and included the effects of ACE-inhibitors, anti-hypertensive and anti-thrombotic drugs, serum lipid reducing agents, anti-diabetic, anti-Parkinson, anti-epileptic, anti-inflammatory and anti-rheumatic medication, systemic corticosteroids, psycholepticand psycho-analeptic agents. No effect of medication on plasma BDNF was observed.

Table 1

Baseline characteristics of the study population

\begin{tabular}{|c|c|c|c|c|}
\hline & $\begin{array}{c}\text { Total } \\
N=758\end{array}$ & $\begin{array}{l}\text { Incident dementia } \\
\qquad N=131\end{array}$ & $\begin{array}{c}\text { No dementia } \\
N=627\end{array}$ & $p$ \\
\hline Age, y & $73.19(7.47)$ & $75.76(7.44)$ & $72.75(7.44)$ & $<0.001$ \\
\hline Women & $419(55.28 \%)$ & $81(61.83 \%)$ & $338(53.91 \%)$ & $<0.001$ \\
\hline Plasma BDNF, pg/mL & $139.57(162.88)$ & $138.27(148.65)$ & $139.84(165.81)$ & 0.92 \\
\hline Physical Activity (total METh) & $87.96(49.10)$ & $88.64(47.76)$ & $87.82(49.42)$ & 0.86 \\
\hline Apolipoprotein $\mathrm{E} \varepsilon 4$ carrier & $216(28.50 \%)$ & $48(36.64 \%)$ & $168(26.79 \%)$ & 0.003 \\
\hline Apolipoprotein E $\varepsilon 4$ homozygote & $12(1.65 \%)$ & $7(22.58 \%)$ & $5(0.80 \%)$ & $<0.001$ \\
\hline Systolic blood pressure & $143.37(20.66)$ & $140.44(20.22)$ & $143.98(20.72)$ & 0.72 \\
\hline Diastolic blood pressure & $74.77(10.97)$ & $72.94(10.09)$ & $75.15(11.11)$ & 0.04 \\
\hline Middle level of education & $324(42.74 \%)$ & $41(31.30 \%)$ & $283(45.14 \%)$ & 0.004 \\
\hline High level of education & $61(8.05 \%)$ & $14(10.69 \%)$ & $47(7.50 \%)$ & 0.22 \\
\hline Depressive symptoms & $4.12(6.31)$ & $5.52(7.24)$ & $3.83(6.06)$ & 0.005 \\
\hline Body mass index & $26.62(3.97)$ & $26.62(3.35)$ & $26.62(4.09)$ & 0.99 \\
\hline Anxiety & $50(6.60 \%)$ & $13(9.92 \%)$ & $37(5.90 \%)$ & 0.09 \\
\hline Glucose, $\mathrm{mmol} / \mathrm{L}$ & $5.87(1.43)$ & $5.80(1.15)$ & $5.88(1.49)$ & 0.55 \\
\hline Total cholesterol, $\mathrm{mmol} / \mathrm{L}$ & $5.81(0.97)$ & $5.82(0.91)$ & $5.81(0.98)$ & 0.93 \\
\hline HDL-cholesterol, $\mathrm{mmol} / \mathrm{L}$ & $1.41(0.40)$ & $1.45(0.41)$ & $1.40(0.40)$ & 0.13 \\
\hline MMSE & $27.68(1.92)$ & $27.30(2.03)$ & $27.76(1.88)$ & 0.01 \\
\hline Current smoking & $121(15.96 \%)$ & $13(9.92 \%)$ & $108(17.22 \%)$ & 0.04 \\
\hline Former smoking & $367(48.42 \%)$ & $64(48.85 \%)$ & $303(48.33 \%)$ & 0.91 \\
\hline Alcohol intake g/day & $11.82(16.45)$ & $11.31(13.96)$ & $11.93(16.93)$ & 0.69 \\
\hline
\end{tabular}

Means and standard deviations, number and percentage reported. $P$-values are based on univariate analysis of variance and Pearson's chisquare test. Anxiety is expressed as self-reported presence of anxious feelings yes/no. BDNF, brain-derived neurotropic factor; pg/mL, picogram per milliliter, METh, metabolic equivalent of task hour; mmol/L, millimole per liter; g/day, gram per day; BMI, body mass index; HDL, high density lipoprotein; MMSE, Mini-Mental State Examination. 
Table 2

Average plasma BDNF values stratified by group

\begin{tabular}{|c|c|c|c|}
\hline & $\mathrm{N}$ & Plasma BDNF & $p$ \\
\hline Women & 339 & $142.17(163.48)$ & \\
\hline Ien & 419 & $136.37(162.32)$ & 0.63 \\
\hline o dementia & 627 & $139.84(165.81)$ & \\
\hline $\begin{array}{l}\text { Incident dementia } \\
\text { all cause }\end{array}$ & 131 & $138.27(148.65)$ & 0.92 \\
\hline $\begin{array}{l}\text { Incident Alzheimer's } \\
\text { disease }\end{array}$ & 104 & $151.49(157.33)$ & \\
\hline Incident dementia other & 27 & 87.35 (95.07) & 0.045 \\
\hline Carrier of $A P O E \varepsilon$ & 216 & $138.75(134.72)$ & \\
\hline $\begin{array}{l}\text { Non carrier of } \\
\quad A P O E \varepsilon 4 \text { allele }\end{array}$ & 542 & $139.90(170.29)$ & 0.93 \\
\hline Low level o & 369 & 134 & \\
\hline ion & 323 & 148 & \\
\hline High le & 60 & $112.06(118.90)$ & 0.21 \\
\hline Current si & 121 & $190.12(212.92)$ & \\
\hline Former smoker & 367 & $134.69(157.79)$ & \\
\hline Never s & 270 & $123.56(138.28)$ & 0.00 \\
\hline $\begin{array}{l}\text { Low level of } \\
\text { physical activity }\end{array}$ & 249 & $149.78(169.39)$ & \\
\hline $\begin{array}{l}\text { Moderate level of } \\
\text { physical activity }\end{array}$ & 249 & $146.69(184.45)$ & \\
\hline $\begin{array}{l}\text { High level of } \\
\text { physical activity }\end{array}$ & 249 & $123.55(132.48)$ & 0.15 \\
\hline \multicolumn{4}{|c|}{$\begin{array}{l}\text { Group means and standard deviations reported. } P \text {-values are based } \\
\text { on univariate comparison of group means. Level of physical activ- } \\
\text { ity is expressed in tertile groups of the total number of Metabolic } \\
\text { Equivalent of Task hours. BDNF, brain-derived neurotropic fac- } \\
\text { tor expressed in pg/mL (picogram per milliliter); APOE } \varepsilon 4 \text {, } \\
\text { Apolipoprotein E } \varepsilon 4 \text {. }\end{array}$} \\
\hline
\end{tabular}

Table 3

Summary of regression analysis predicting variation in BDNF plasma level in the sub-cohort $\mathrm{N}=758$

\begin{tabular}{lcccc}
\hline Variable & $B$ & $S E(B)$ & $\beta$ & $p$ \\
\hline Age & 0.003 & 0.001 & 0.11 & 0.002 \\
Sex & 0.03 & 0.01 & 0.03 & 0.09 \\
Middle level of education & 0.02 & 0.01 & 0.06 & 0.13 \\
High level of education & -0.01 & 0.02 & -0.01 & 0.80 \\
Body mass index & -0.001 & 0.00 & -0.04 & 0.32 \\
Diabetes mellitus & -0.01 & 0.01 & -0.04 & 0.24 \\
Total cholesterol & 0.01 & 0.01 & 0.09 & 0.06 \\
Systolic blood pressure & 0.00 & 0.00 & -0.04 & 0.23 \\
APOE \&4 status & 0.001 & 0.01 & 0.002 & 0.94 \\
Depressive symptoms & -0.002 & 0.001 & -0.07 & 0.09 \\
Anxiety & 0.01 & 0.03 & 0.02 & 0.65 \\
Alcohol & 0.00 & 0.00 & 0.03 & 0.39 \\
Current smoking & 0.08 & 0.01 & 0.18 & $<0.001$ \\
Former smoking & 0.02 & 0.01 & 0.07 & 0.13 \\
Standardized physical activity & -0.01 & 0.01 & -0.07 & 0.06 \\
\hline APOE & & & &
\end{tabular}

APOE $\varepsilon 4$, Apolipoprotein E $\varepsilon 4$.

\section{Survival analyses: $B D N F$ and the risk of dementia}

The Cox proportional hazard analysis of the risk of dementia did not show evidence for a relation between the level of plasma BDNF at baseline and
Table 4

Association between plasma BDNF level and risk of dementia

\begin{tabular}{|c|c|c|}
\hline & $\begin{array}{c}\text { Incident } \\
\text { dementia } \\
\text { n/N 131/758 } \\
\text { HR }(95 \% \text { CI })\end{array}$ & $\begin{array}{c}\text { Incident } \\
\text { Alzheimer's } \\
\text { disease n/N 104/758 } \\
\text { HR }(95 \% \mathrm{CI})\end{array}$ \\
\hline Plasma BDNF & $\begin{array}{c}0.99(0.84-1.16) \\
\chi^{2}(3)=2.88 p=0.41\end{array}$ & $\begin{array}{c}1.06(0.92-1.23) \\
\chi^{2}(3)=3.60 p=0.31\end{array}$ \\
\hline
\end{tabular}

Adjusted for age and sex. Plasma BDNF values are standardized. BDNF, Brain-derived neurotropic factor.

risk of dementia (Table 4). The observed hazard ratio (HR) per SD increase in plasma BDNF is $0.99(95 \%$ CI 0.84-1.55) $\chi^{2}(3)=2.88 p=0.41$. Adjustment for the competing risk of death in the competing risk regression only altered the sub distribution hazard of plasma BDNF on the risk of dementia 0.95 (95\% CI $0.80-1.13) \chi^{2}(3)=15.73 p=0.001$. Analysis per tertile of plasma BDNF levels, using the first tertile as reference, did also not show any significant differences in dementia risk for those with different levels of plasma BDNF at baseline [HR moderate versus low 0.91 (95\% CI $0.65-1.29$ ); HR high versus low 1.08 (95\% CI $0.78-1.49)$. Figure 2 shows the cumulative incidence curves of dementia per tertile of plasma BDNF, adjusted for age and sex.

Congruent hazard ratios were found for the incidence of AD: HR 1.06 (95\% CI 0.92-1.23) $\chi^{2}(3)=3.60 p=0.31$ (Table 4). Additional adjustment for education level, metabolic factors (total cholesterol, HDL-cholesterol, glucose, BMI, systolic blood pressure), diabetes mellitus, depressive symptoms, anxiety $(\mathrm{y} / \mathrm{n})$, alcohol consumption, smoking status, physical activity level, or APOE $\varepsilon 4$ carrier status did not change the association between plasma BDNF and dementia risk. When testing for effect modification, no evidence for multiplicative interactions between plasma BDNF level and $A P O E \varepsilon 4$ carrier status, education level, sex or smoking status was found.

\section{DISCUSSION}

In our cohort study with a follow-up period of up to 16 years, we did not find an association between BDNF levels and dementia risk. We found that a higher plasma BDNF level at baseline is associated with higher age, female sex and higher prevalence of smoking. Plasma BDNF was not associated with total physical activity level or amount of moderate to vigorous activity. 
Our findings with regard to dementia risk are in contrast with the only other follow-up study on the relation between peripheral BDNF and future dementia risk, in which higher serum BDNF levels were associated with a lower incidence of dementia over a follow-up period of 10 years [25]. However, when conducting a sensitivity analysis, Weinstein et al. concluded the association was confined to specific subgroups of participants, i.e., women, older participants ( $>80$ years) and participants with at least a college degree. In the present study, subgroup analyses did not yield different results. Our results also deviate from the observed elevations in plasma BDNF in patients with $\mathrm{AD}$ reported by Elahi et al [24]. Although the cumulative incidence rate of dementia for those with the highest level of plasma BDNF is elevated compared to lower levels of plasma BDNF, no significant differences in dementia risk are observed. The discrepancy might be related to the course of $\mathrm{AD}$, suggesting that peripheral BDNF concentrations change as a result of AD pathology and mark disease progression and severity of the cognitive deficit [61].

The absence of an association between BDNF and dementia risk is in line with the findings of longitudinal studies investigating cognitive decline. For instance, Nettiksimmons et al. and Driscoll et al. found no prospective association between blood BDNF levels and cognitive decline in healthy older adults [27, 28]. Our results also correspond with the Mendelian Randomization studies that have so far failed to establish a robust association between polymorphisms of the BDNF gene and AD [62].

We found a positive association between age and plasma BDNF, in line with two previous reports in younger age groups $[63,64]$, but in conflict with several studies, in comparable age groups, reporting a negative association [25, 65-67] or no association $[21,68-71]$. The findings on the association between age and BDNF level therefore seem unclear, while age is the major determinant of a wide variety of diseases in the population.

Of note is that we found that current smoking is also associated with elevated blood plasma BDNF levels. This finding is in accordance with results of previous large cross-sectional and longitudinal studies $[25,33$, $67,72]$. The fact that the direction of the association between plasma BDNF levels and both smoking and aging, is similar, is as anticipated, given that both are drivers of inflammation, disease and mortality. This association supports the hypothesis that BDNF is a key regulator in the neuroimmune axis [73]. On the one hand, inflammatory responses are known to cause a reduction in BDNF expression, a process that may lead to impairments in neuroplasticity and cognition $[73,74]$. On the other hand, anti-inflammatory processes also require the regulation of BDNF signaling pathways that promote neuroprotection and survival $[73,75]$.

Strengths of the present study are the use of plasma BDNF as predictor of dementia risk, the extended follow-up period of up to 16 years, and the availability of information on multiple confounders.

However, it is important to note that the detection limits and average plasma BDNF levels obtained by the multiplex immunoassay used in the present study differ from those obtained by more sensitive single-molecule arrays [76, 77]. The reliability of our assessment is warranted by adherence to standard operating procedures [45] and quality control [46] and is strengthened by the replication of the positive association between circulating BDNF and smoking $[25,33,67,72]$.

In conclusion, the current study sheds new light on the association between plasma BDNF and the neuropathology of dementia. The results indicate that alterations in peripheral plasma BDNF levels do not increase the risk of dementia. The positive association between plasma BDNF levels and age and smoking, both drivers of dementia risk, raises the question whether larger studies are needed.

\section{ACKNOWLEDGMENTS}

The authors are grateful to the study participants, the staff from the Rotterdam Study and the participating general practitioners and pharmacists.

The Rotterdam Study is funded by Erasmus Medical Center and Erasmus University, Rotterdam, Netherlands Organization for the Health Research and Development (ZonMw), the Research Institute for Diseases in the Elderly (RIDE), the Ministry of Education, Culture and Science, the Ministry for Health, Welfare, and Sports, the European Commission (DG XII), and the Municipality of Rotterdam. The work described here is funded by European Union's Horizon 2020 Research and Innovation program as part of the CoSTREAM project (Common mechanisms and pathways in Stroke and Alzheimer's disease, http://www.costream.eu, grant 667375) and by the Netherlands Organization for the Health Research and Development (ZonMw) as part of the projects Memorabel (Dementia research and inno- 
vation program - grant 733050303) and PERADES (Defining Genetic, Polygenic and Environmental Risk for Alzheimer's Disease using multiple powerful cohorts, focused Epigenetics and Stem cell metabolomics - grant 733051021).

Authors' disclosures available online (https:// www.j-alz.com/manuscript-disclosures/20-0371r3).

\section{REFERENCES}

[1] Marosi K, Mattson MP (2014) BDNF mediates adaptive brain and body responses to energetic challenges. Trends Endocrinol Metab 25, 89-98.

[2] Mizui T, Ishikawa Y, Kumanogoh H, Kojima M (2016) Neurobiological actions by three distinct subtypes of brain-derived neurotrophic factor: Multi-ligand model of growth factor signaling. Pharmacol Res 105, 93-98.

[3] Park H, Poo MM (2013) Neurotrophin regulation of neural circuit development and function. Nat Rev Neurosci 14, 723.

[4] Ghosh A, Carnahan J, Greenberg ME (1994) Requirement for BDNF in activity-dependent survival of cortical neurons. Science 263, 1618-1623.

[5] Lindholm D, Carroll P, Tzimagiorgis G, Thoenen H (1996) Autocrine-paracrine regulation of hippocampal neuron survival by IGF-1 and the neurotrophins BDNF, NT-3 and NT-4. Eur J Neurosci 8, 1452-1460.

[6] Alderson RF, Alterman AL, Barde YA, Lindsay RM (1990) Brain-derived neurotrophic factor increases survival and differentiated functions of rat septal cholinergic neurons in culture. Neuron 5, 297-306.

[7] Hyman C, Hofer M, Barde YA, Juhasz M, Yancopoulos GD, Squinto SP, Lindsay RM (1991) BDNF is a neurotrophic factor for dopaminergic neurons of the substantia nigra. Nature 350, 230-232.

[8] Lu B, Nagappan G, Guan X, Nathan PJ, Wren P (2013) BDNF-based synaptic repair as a disease-modifying strategy for neurodegenerative diseases. Nat Rev Neurosci 14, 401-416.

[9] Figurov A, Pozzo-Miller LD, Olafsson P, Wang T, Lu B (1996) Regulation of synaptic responses to high-frequency stimulation and LTP by neurotrophins in the hippocampus. Nature 381, 706-709.

[10] Xu B, Gottschalk W, Chow A, Wilson RI, Schnell E, Zang K, Wang D, Nicoll RA, Lu B, Reichardt LF (2000) The role of brain-derived neurotrophic factor receptors in the mature hippocampus: Modulation of long-term potentiation through a presynaptic mechanism involving trkB. $J$ Neurosci 20, 6888-6897.

[11] Bramham CR, Messaoudi E (2005) BDNF function in adult synaptic plasticity: The synaptic consolidation hypothesis. Prog Neurobiol 76, 99-125.

[12] Lattanzio F, Carboni L, Carretta D, Rimondini R, Candeletti S, Romualdi P (2014) Human apolipoprotein E4 modulates the expression of Pin1, Sirtuin 1, and Presenilin 1 in brain regions of targeted replacement apoE mice. Neuroscience 256, 360-369.

[13] Erickson KI, Voss MW, Prakash RS, Basak C, Szabo A, Chaddock L, Kim JS, Heo S, Alves H, White SM, Wojcicki TR, Mailey E, Vieira VJ, Martin SA, Pence BD, Woods JA, McAuley E, Kramer AF (2011) Exercise training increases size of hippocampus and improves memory. Proc Natl Acad Sci U S A 108, 3017-3022.

[14] Komulainen P, Pedersen M, Hänninen T, Bruunsgaard H, Lakka TA, Kivipelto M, Hassinen M, Rauramaa TH, Pedersen BK, Rauramaa R (2008) BDNF is a novel marker of cognitive function in ageing women: The DR's EXTRA Study. Neurobiol Learn Mem 90, 596-603.

[15] Song JH, Yu JT, Tan L (2015) Brain-derived neurotrophic factor in Alzheimer's disease: Risk, mechanisms, and therapy. Mol Neurobiol 52, 1477-1493.

[16] Ferrer I, Marín C, Rey MJ, Ribalta T, Goutan E, Blanco R, Tolosa E, Martí E (1999) BDNF and full-length and truncated TrkB expression in Alzheimer disease. Implications in therapeutic strategies. J Neuropathol Exp Neurol 58, 729-739.

[17] Holsinger RMD, Schnarr J, Henry P, Castelo VT, Fahnestock M (2000) Quantitation of BDNF mRNA in human parietal cortex by competitive reverse transcriptionpolymerase chain reaction: Decreased levels in Alzheimer's disease. Mol Brain Res 76, 347-354.

[18] Blasko I, Lederer W, Oberbauer H, Walch T, Kemmler G, Hinterhuber H, Marksteiner J, Humpel C (2005) Measurement of thirteen biological markers in CSF of patients with Alzheimer's disease and other dementias. Dement Geriatr Cogn Disord 21, 9-15.

[19] O'Bryant SE, Hobson V, Hall JR, Waring SC, Chan W, Massman P, Lacritz L, Cullum CM, Diaz-Arrastia R, Texas Alzheimer's Research Consortium (2009) Brainderived neurotrophic factor levels in Alzheimer's disease. J Alzheimers Dis 17, 337-341.

[20] O'Bryant SE, Hobson VL, Hall JR, Barber RC, Zhang S, Johnson L, Diaz-Arrastia R, Texas Alzheimer's Research Consortium (2011) Serum brain-derived neurotrophic factor levels are specifically associated with memory performance among Alzheimer's disease cases. Dement Geriatr Cogn Disord 31, 31-6.

[21] Angelucci F, Spalletta G, Iulio F, Ciaramella A, Salani F, Varsi A, Gianni W, Sancesario G, Caltagirone C, Bossu P (2010) Alzheimer's disease (AD) and mild cognitive impairment (MCI) patients are characterized by increased BDNF serum levels. Curr Alzheimer Res 7, 15-20.

[22] Kim BY, Lee SH, Graham PL, Angelucci F, Lucia A, ParejaGaleano H, Leyhe T, Turana Y, Lee IR, Yoon JH, Shin J Il (2017) Peripheral brain-derived neurotrophic factor levels in Alzheimer's disease and mild cognitive impairment: A comprehensive systematic review and meta-analysis. Mol Neurobiol 54, 7297-7311.

[23] Ng TKS, Ho CSH, Tam WWS, Kua EH, Ho RCM (2019) Decreased serum brain-derived neurotrophic factor (BDNF) levels in patients with Alzheimer's disease (AD): A systematic review and meta-analysis. Int J Mol Sci 20, $1-26$.

[24] Elahi FM, Casaletto KB, La R, Walters SM, Harvey D, Wolf A, Edwards L, Rivera-Contreras W, Karydas A, Cobigo Y, Rosen HJ, Decarli C, Miller BL, Rabinovici GD, Kramer JH (2020) Plasma biomarkers of astrocytic and neuronal dysfunction in early- and late-onset Alzheimer's disease. Alzheimers Dement 16, 681-695.

[25] Weinstein G, Beiser AS, Choi SH, Preis SR, Chen TC, Vorgas D, Au R, Pikula A, Wolf PA, DeStefano AL, Vasan RS, Seshadri S (2014) Serum brain-derived neurotrophic factor and the risk for dementia: The Framingham Heart Study. JAMA Neurol 71, 55-61.

[26] Laske C, Stellos K, Hoffmann N, Stransky E, Straten G, Eschweiler GW, Leyhe T (2011) Higher BDNF serum 
levels predict slower cognitive decline in Alzheimer's disease patients. Int $J$ Neuropsychopharmacol 14, 399-404.

[27] Nettiksimmons J, Simonsick EM, Harris T, Satterfield S, Rosano C, Yaffe K (2014) The associations between serum brain-derived neurotrophic factor, potential confounders, and cognitive decline: A longitudinal study. PLoS One 9, e91339.

[28] Driscoll I, Martin B, An Y, Maudsley S, Ferrucci L, Mattson MP, Resnick SM (2012) Plasma BDNF is associated with age-related white matter atrophy but not with cognitive function in older, non-demented adults. PLoS One 7, e35217.

[29] Giese M, Unternaehrer E, Brand S, Calabrese P, HolsboerTrachsler E, Eckert A (2013) The interplay of stress and sleep impacts BDNF level. PLoS One 8, e76050.

[30] Zielinski MR, Kim Y, Karpova SA, McCarley RW, Strecker RE, Gerashchenko D (2014) Chronic sleep restriction elevates brain interleukin-1 beta and tumor necrosis factoralpha and attenuates brain-derived neurotrophic factor expression. Neurosci Lett 580, 27-31.

[31] Molendijk ML, Spinhoven P, Polak M, Bus BAA, Penninx BWJH, Elzinga BM (2014) Serum BDNF concentrations as peripheral manifestations of depression: Evidence from a systematic review and meta-analyses on 179 associations (N=9484). Mol Psychiatry 19, 791-800.

[32] Phillips C (2017) Brain-derived neurotrophic factor, depression, and physical activity: Making the neuroplastic connection. Neural Plast 2017, 7260130.

[33] Bus BAA, Molendijk ML, Penninx BJWH, Buitelaar JK, Kenis G, Prickaerts J, Elzinga BM, Voshaar RCCO (2011) Determinants of serum brain-derived neurotrophic factor. Psychoneuroendocrinology 36, 228-239.

[34] Neeper SA, Góauctemez-Pinilla F, Choi J, Cotman C (1995) Exercise and brain neurotrophins. Nature 373, 109-109.

[35] Ahlskog JE, Geda YE, Graff-Radford NR, Petersen RC (2011) Physical exercise as a preventive or disease-modifying treatment of dementia and brain aging. Mayo Clin Proc 86, 876-884.

[36] Coelho FGDM, Gobbi S, Andreatto CAA, Corazza DI, Pedroso RV, Santos-Galduróz RF (2013) Physical exercise modulates peripheral levels of brain-derived neurotrophic factor (BDNF): A systematic review of experimental studies in the elderly. Arch Gerontol Geriatr 56, 10-15.

[37] Huang T, Larsen KT, Ried-Larsen M, Møller NC, Andersen LB (2014) The effects of physical activity and exercise on brain-derived neurotrophic factor in healthy humans: A review. Scand J Med Sci Sports 24, 1-10.

[38] Szuhany KL, Bugatti M, Otto MW (2015) A meta-analytic review of the effects of exercise on brain-derived neurotrophic factor. J Psychiatr Res 60, 56-64.

[39] Vaynman S, Ying Z, Gómez-Pinilla F (2004) Exercise induces BDNF and synapsin I to specific hippocampal subfields. J Neurosci Res 76, 356-362.

[40] Duan W, Lee J, Guo Z, Mattson MP (2001) Dietary restriction stimulates BDNF production in the brain and thereby protects neurons against excitotoxic injury. $\mathrm{J} \mathrm{Mol} \mathrm{Neurosci}$ 16, 1-12.

[41] Lee J, Duan W, Long JM, Ingram DK, Mattson MP (2000) Dietary restriction increases the number of newly generated neural cells, and BDNF expression, in the dentate gyrus of rats. J Mol Neurosci 15, 99-108.

[42] Chan KL, Tong KY, Yip SP (2008) Relationship of serum brain-derived neurotrophic factor (BDNF) and health- related lifestyle in healthy human subjects. Neurosci Lett 447, 124-128.

[43] Ikram MA, Brusselle GGO, Murad SD, van Duijn CM, Franco OH, Goedegebure A, Klaver CCW, Nijsten TEC, Peeters RP, Stricker BH, Tiemeier H, Uitterlinden AG, Vernooij MW, Hofman A (2017) The Rotterdam Study: 2018 update on objectives, design and main results. Eur J Epidemiol 32, 807-850.

[44] Soares HD, Chen Y, Sabbagh M, Rohrer A, Schrijvers E, Breteler M (2009) Identifying early markers of alzheimer's disease using quantitative multiplex proteomic immunoassay panels. Ann N Y Acad Sci 1180, 56-67.

[45] Myriad RBM Myriad RBM Operational Procedures. https://myriadrbm.com/scientific-media/myriad-rbmoperational-procedures-white-paper.

[46] Welsh BT, Mapes J (2013) An Overview of Assay Quality Systems at RBM, Inc. https://rbm.myriad.com/scientificliterature/white-papers/quality-control-white-paper/.

[47] Folstein MF, Folstein SE, McHugh PR (1975) "Mini-mental state". A practical method for grading the cognitive state of patients for the clinician. J Psychiatr Res 12, 189-198.

[48] Copeland JRM, Kelleher MJ, Kellett JM, Gourlay AJ, Gurland BJ, Fleiss JL, Sharpe L (1976) A semi-structured clinical interview for the assessment of diagnosis and mental state in the elderly: The Geriatric Mental State Schedule: I. Development and reliability. Psychol Med 6, 439.

[49] Roth M, Tym E, Mountjoy CQ, Huppert FA, Hendrie H, Verma S, Goddard R (1986) CAMDEX. A standardised instrument for the diagnosis of mental disorder in the elderly with special reference to the early detection of dementia. $\mathrm{Br}$ J Psychiatry 149, 698-709.

[50] American Psychiatric Association., American Psychiatric Association. Work Group to Revise DSM-III (1987) Diagnostic and statistical manual of mental disorders: DSM-III-R. American Psychiatric Association.

[51] McKhann GM, Knopman DS, Chertkow H, Hyman BT, Jack CR, Kawas CH, Klunk WE, Koroshetz WJ, Manly JJ, Mayeux R, Mohs RC, Morris JC, Rossor MN, Scheltens P, Carrillo MC, Thies B, Weintraub S, Phelps $\mathrm{CH}$ (2011) The diagnosis of dementia due to Alzheimer's disease: Recommendations from the National Institute on Aging-Alzheimer's Association workgroups on diagnostic guidelines for Alzheimer's disease. Alzheimers Dement 7, 263-269.

[52] Caspersen CJ, Bloemberg BPM, Saris WHM, Merritt RK, Kromhout D (1991) The prevalence of selected physical activities and their relation with coronary heart disease risk factors in elderly men: The Zutphen study, 1985. Am J Epidemiol 133, 1078-1092.

[53] Westerturp KR, Saris W, Bloemberg B, Kempen K, Caspersen CJ, Kromhout D (1992) Validation of the Zutphen Physical Activity Questionaire for the elderly with doubly labeled water. Med Sci Sport Exerc 24, S68.

[54] Ainsworth BE, Haskell WL, Herrmann SD, Meckes N, Bassett DR, Tudor-Locke C, Greer JL, Vezina J, Whitt-Glover MC, Leon AS (2011) 2011 compendium of physical activities: A second update of codes and MET values. Med Sci Sports Exerc 43, 1575-1581.

[55] Koolhaas CM, Dhana K, Golubic R, Schoufour JD, Hofman A, Van Rooij FJA, Franco OH (2016) Physical activity types and coronary heart disease risk in middle-aged and elderly persons: The Rotterdam Study. Am J Epidemiol 183, 729738.

[56] Beekman ATF, Deeg DJH, Van Limbeek J, Braam AW, De Vries MZ, Van Tilburg W (1997) Criterion validity 
of the Center for Epidemiologic Studies Depression scale (CES-D): Results from a community-based sample of older subjects in the Netherlands. Psychol Med 27, 231-235.

[57] Radloff LS (1977) The CES-D Scale: A self-report depression scale for research in the general population. Appl Psychol Meas 1, 385-401.

[58] Fine JP, Gray RJ (1999) A proportional hazards model for the subdistribution of a competing risk. J Am Stat Assoc 94, 496-509.

[59] Wolters FJ, Chibnik LB, Waziry R, Anderson R, Berr C, Beiser A, Bis JC, Blacker D, Bos D, Brayne C, Dartigues J-F, Darweesh SK, Davis-Plourde KL, de Wolf F, Debette S, Dufouil C, Fornage M, Goudsmit J, Grasset L, Gudnason V, Hadjichrysanthou C, Helmer C, Ikram MA, Ikram MK, Joas E, Kern S, Kuller LH, Launer L, Lopez O, Matthews FE, McRae-McKee K, Meirelles O, Mosley TH, Pase MP, Psaty BM, Satizabal CL, Seshadri S, Skoog I, Stephan BC, Wetterberg H, Wong MM, Zettergren A, Hofman A (2020) 27-year time trends in dementia incidence in Europe and the US: The Alzheimer Cohorts Consortium. Neurology 95, e519-e531.

[60] Prince M, Wimo A, Guerchet M, Ali G-C, Wu Y-T, Prina M (2015) World Alzheimer Report 2015. The Global Impact of Dementia: An analysis of prevalence, incidence, cost and trends. Alzheimer's Disease International, London.

[61] Laske C, Stransky E, Leyhe T, Eschweiler GW, Wittorf A, Richartz E, Bartels M, Buchkremer G, Schott K (2006) Stage-dependent BDNF serum concentrations in Alzheimer's disease. J Neural Transm 113, 1217-1224.

[62] Ji H, Dai D, Wang Y, Jiang D, Zhou X, Lin P, Ji X, Li J, Zhang Y, Yin H, Chen R, Zhang L, Xu M, Duan S, Wang Q (2015) Association of BDNF and BCHE with Alzheimers disease Meta-analysis based on 56 genetic case-control studies of 12,563 cases and 12,622 controls. Exp Ther Med 9, 18311840.

[63] Jung SH, Kim J, Davis JM, Blair SN, Cho H (2011) Association among basal serum BDNF, cardiorespiratory fitness and cardiovascular disease risk factors in untrained healthy Korean men. Eur J Appl Physiol 111, 303-311.

[64] Lang UE, Hellweg R, Gallinat J (2004) BDNF serum concentrations in healthy volunteers are associated with depression-related personality traits. Neuropsychopharmacology 29, 795-798.

[65] Ziegenhorn AA, Schulte-Herbrüggen O, Danker-Hopfe $\mathrm{H}$, Malbranc M, Hartung H-D, Anders D, Lang UE, Steinhagen-Thiessen E, Schaub RT, Hellweg R (2007) Serum neurotrophins-A study on the time course and influencing factors in a large old age sample. Neurobiol Aging 28, 1436-1445.

[66] Golden E, Emiliano A, Maudsley S, Windham BG, Carlson OD, Egan JM, Driscoll I, Ferrucci L, Martin B, Mattson MP (2010) Circulating brain-derived neurotrophic factor and indices of metabolic and cardiovascular health: Data from the Baltimore Longitudinal Study of Aging. PLoS One 5, e10099.

[67] Weinstein G, Preis SR, Beiser AS, Kaess B, Chen TC, Satizabal C, Rahman F, Benjamin EJ, Vasan RS, Seshadri S (2017) Clinical and environmental correlates of serum BDNF: A descriptive study with plausible implications for AD research. Curr Alzheimer Res 14, 722-730.

[68] Gunstad J, Benitez A, Smith J, Glickman E, Spitznagel MB, Alexander T, Juvancic-Heltzel J, Murray L (2008) Serum brain-derived neurotrophic factor is associated with cognitive function in healthy older adults. J Geriatr Psychiatry Neurol 21, 166-170.

[69] Laske C, Stransky E, Leyhe T, Eschweiler GW, Maetzler W, Wittorf A, Soekadar S, Richartz E, Koehler N, Bartels M, Buchkremer G, Schott K (2007) BDNF serum and CSF concentrations in Alzheimer's disease, normal pressure hydrocephalus and healthy controls. J Psychiatr Res 41, 387-394.

[70] Yasutake C, Kuroda K, Yanagawa T, Okamura T, Yoneda $\mathrm{H}$ (2006) Serum BDNF, TNF- $\alpha$ and IL-1 $\beta$ levels in dementia patients. Eur Arch Psychiatry Clin Neurosci 256, 402-406.

[71] Minelli A, Zanardini R, Bonvicini C, Sartori R, Pedrini L, Gennarelli M, Bocchio-Chiavetto L (2011) BDNF serum levels, but not BDNF Val66Met genotype, are correlated with personality traits in healthy subjects. Eur Arch Psychiatry Clin Neurosci 261, 323-329.

[72] Jamal M, Van der Does W, Elzinga BM, Molendijk ML, Penninx BWJH (2015) Association between smoking, nicotine dependence, and BDNF Val 66 Met polymorphism with BDNF concentrations in serum. Nicotine Tob Res 17, 323329.

[73] Jin Y, Sun LH, Yang W, Cui RJ, Xu SB (2019) The role of $\mathrm{BDNF}$ in the neuroimmune axis regulation of mood disorders. Front Neurol 10, 515.

[74] Calabrese F, Rossetti AC, Racagni G, Gass P, Riva MA, Molteni R (2014) Brain-derived neurotrophic factor: A bridge between inflammation and neuroplasticity. Front Cell Neurosci 8, 430.

[75] Lima Giacobbo B, Doorduin J, Klein HC, Dierckx RAJO, Bromberg E, de Vries EFJ (2019) Brain-derived neurotrophic factor in brain disorders: Focus on neuroinflammation. Mol Neurobiol 56, 3295-3312.

[76] van den Heuvel L, Suliman S, Malan-Müller S, Hemmings S, Seedat S (2016) Brain-derived neurotrophic factor Val66met polymorphism and plasma levels in road traffic accident survivors. Anxiety Stress Coping 29, 616-629.

[77] Choi SW, Bhang S, Ahn JH (2011) Diurnal variation and gender differences of plasma brain-derived neurotrophic factor in healthy human subjects. Psychiatry Res 186, 427430 . 